\title{
The $28+28$ day design is an effective sampling time for analyzing mutant frequencies in rapidly proliferating tissues of MutaMouse animals
}

\author{
Francesco Marchetti ${ }^{1}\left(\mathbb{0} \cdot\right.$ Gu Zhou $^{1} \cdot$ Danielle LeBlanc $^{1} \cdot$ Paul A. White $^{1} \cdot$ Andrew Williams $^{1} \cdot$ Carole L. Yauk $^{1,2}$ (D) $^{-}$ \\ George R. Douglas ${ }^{1}$
}

Received: 13 October 2020 / Accepted: 4 January 2021 / Published online: 28 January 2021

(c) Crown 2021

\begin{abstract}
The Organisation for Economic Co-Operation and Development Test Guideline 488 (TG 488) uses transgenic rodent models to generate in vivo mutagenesis data for regulatory submission. The recommended design in TG 488, 28 consecutive daily exposures with tissue sampling three days later $(28+3 \mathrm{~d})$, is optimized for rapidly proliferating tissues such as bone marrow (BM). A sampling time of 28 days $(28+28 \mathrm{~d})$ is considered more appropriate for slowly proliferating tissues (e.g., liver) and male germ cells. We evaluated the impact of the sampling time on mutant frequencies (MF) in the BM of MutaMouse males exposed for 28 days to benzo[a]pyrene (BaP), procarbazine (PRC), isopropyl methanesulfonate (iPMS), or triethylenemelamine (TEM) in dose-response studies. BM samples were collected $+3 \mathrm{~d},+28 \mathrm{~d},+42 \mathrm{~d}$ or $+70 \mathrm{~d}$ post exposure and MF quantified using the lac $Z$ assay. All chemicals significantly increased MF with maximum fold increases at $28+3 \mathrm{~d}$ of 162.9 , 6.6, 4.7 and 2.8 for BaP, PRC, iPMS and TEM, respectively. MF were relatively stable over the time period investigated, although they were significantly increased only at $28+3 \mathrm{~d}$ and $28+28 \mathrm{~d}$ for TEM. Benchmark dose (BMD) modelling generated overlapping BMD confidence intervals among the four sampling times for each chemical. These results demonstrate that the sampling time does not affect the detection of mutations for strong mutagens. However, for mutagens that produce small increases in MF, sampling times greater than 28 days may produce false-negative results. Thus, the $28+28 \mathrm{~d}$ protocol represents a unifying protocol for simultaneously assessing mutations in rapidly and slowly proliferating somatic tissues and male germ cells.
\end{abstract}

Keywords Benzo[a]pyrene $\cdot$ Isopropyl methanesulfonate $\cdot$ Procarbazine $\cdot$ Triethylenemelamine $\cdot$ Benchmark dose

\section{Introduction}

Transgenic rodent (TGR) mutation models currently represent the most effective tool to evaluate the ability of chemicals to induce mutations in vivo (Lambert et al. 2005; OECD 2009). The use of TGR models to generate in vivo mutagenicity data for regulatory decision-making is described in the Organisation for Economic Co-Operation and Development

Francesco Marchetti

francesco.marchetti@canada.ca

1 Environmental Health Science and Research Bureau, Healthy Environments and Consumer Safety Branch, Health Canada, 251 Sir Frederick Banting Driveway, Ottawa, ON K1A 0K9, Canada

2 Department of Biology, University of Ottawa, Ottawa, ON, Canada
(OECD) test guideline (TG) 488 that has been recently updated (OECD 2020). Unlike some of the other existing in vivo TGs for genotoxicity that measure the response in only one tissue, e.g., the in vivo micronucleus (MN) assay (OECD 2016), TGR models allow the analysis of mutations in virtually any tissue (Gingerich et al. 2014). A noteworthy exception is female germ cells since it is not possible to collect a sufficient number of eggs to obtain enough DNA for conducting the TGR assay (Yauk et al. 2005). While the majority of TGR models detect mostly point mutations and short indels (Lambert et al. 2005), the TGR assay can be easily integrated with the MN assay and other genotoxic endpoints (Hori et al. 2019; Lemieux et al. 2011; Long et al. 2018; Maurice et al. 2019) for the simultaneous analysis of both mutations and chromosomal events.

Germ cell mutagenicity assessment has become increasingly critical because of the wide implementation of the 
Globally Harmonized System (GHS) of classification and labelling of chemicals (United Nations 2017) that requires the assessment of germ cell hazard for proper chemical classification. The TGR assay is currently the only OECD TG that evaluates the same endpoint in both somatic tissues and male germ cells. However, specification of a study design that supports mutagenicity assessment of both somatic tissues and germ cells is challenging due to the unique characteristics of spermatogenesis (e.g., distinct germ cell types, lengthy duration, etc.).

In the mouse, it takes about 49 days to generate mature sperm from spermatogonial stem cells (Marchetti et al. 2018a). During this time, active proliferation is restricted to the spermatogonia compartment and for the last 35 days of male germ cell development there is no DNA replication. The respective times in the rat are approximately 70 and 50 days (Marchetti et al. 2018a). The role of spermatogonial stem cells in maintaining the production of mature male germ cells is well documented and understood (de Rooij 2001). In contrast, the role of hematopoietic stem cells in generating fully developed hematopoietic cells is still unclear, with mounting evidence that hematopoiesis in the adult is sustained by lineage-specific multipotent progenitor cells (Busch et al. 2015; Rodriguez-Fraticelli et al. 2018; Sun et al. 2014). Compared to spermatogenesis, the time necessary to generate mature hematopoietic cells is considerably shorter (Abramsson-Zetterberg et al. 1996); moreover, hematopoietic cells are replicating with an average doubling time of about $10 \mathrm{~h}$ (Pacchierotti et al. 1991). These differences in replicative capacity and cell cycle duration are particularly important because DNA replication and cell division are essential to convert transient DNA damage into a permanent and measurable mutation (Bielas and Heddle 2000), Thus, an experimental design that is adequate for the detection of induced mutations in the bone marrow (BM) may not be appropriate for germ cells, and vice versa.

Two experimental variables that impact the characterization of the mutagenic properties of a chemical are the treatment duration and the elapsed time from the last exposure to tissue collection for analysis (i.e., sampling time). Daily exposures over a period of four weeks are considered a good compromise to allow sufficient accumulation of mutations in slowly proliferating tissues (Heddle et al. 2000) and limit the chance of false positives due to clonal expansion in rapidly proliferating tissues (Thybaud et al. 2003). The sampling time impacts the magnitude of the measured response depending on the rate of proliferation and turnover of the tissue (Heddle et al. 2003), with rapidly proliferating tissues expected to reach the maximum mutant frequency (MF) earlier than slowly proliferating tissues (Thybaud et al. 2003). To maximize the chance of detecting an effect, both exposure time and sampling time should be specific to each tissue. However, such an approach would be impractical because it would require a different set of animals for each tissue and a compromise is necessary to effectively assess responses in both rapidly and slowly proliferating tissues.

The TGR assay is commonly conducted by exposing animals for 28 consecutive days and collecting tissues three days after the last exposure (i.e., $28+3 \mathrm{~d}$ study design). This sampling time was selected based on data demonstrating that MF reached a peak in BM three days after an acute exposure (Thybaud et al. 2003) and to reduce the chances of ex vivo mutations originating from unrepaired DNA damage present in the transgene at the time of tissue collection (Heddle et al. 2003). While TG 488 acknowledges that longer sampling times (e.g., the $28+28 \mathrm{~d}$ design) are more appropriate for slowly proliferating tissues, such as the liver, the assay is most commonly conducted using the $28+3 \mathrm{~d}$ design because of concerns about the impact of extending the sampling time on the detection of mutations in rapidly proliferating tissues. A few cases of an apparent decline in MF observed in BM with increased sampling times have been reported (Heddle et al. 2003; Thybaud et al. 2003). However, some of these results were obtained using a single acute exposure (Hara et al. 1999), which may not be representative of outcomes following a 4 week exposure. Other reported MF declines were not statistically significant (Thybaud et al. 2003). Thus, we contend that there are currently insufficient data to evaluate the full impact of extending the sampling time (e.g., the $28+28 \mathrm{~d}$ design) for the analysis of MF in rapidly proliferating tissues.

A major disadvantage of the $28+3 \mathrm{~d}$ design is the fact that this regimen is ineffective for assessing germ cell mutagenicity. Evaluation of TGR germ cell data obtained with the $28+3 \mathrm{~d}$ design showed that measurement of MF in both caudal sperm and germ cells from the seminiferous tubules is prone to false negatives (Marchetti et al. 2018b; O'Brien et al. 2016). This is because a three-day sampling time does not provide sufficient time for germ cells exposed during the proliferating phase of spermatogenesis, when mutations in the transgene can be induced, to populate the testis (Marchetti et al. 2018a). Conversely, modeling of spermatogenesis showed that the $28+28 \mathrm{~d}$ design significantly improves the exposure sustained during the proliferating phase of spermatogenesis (Marchetti et al. 2018a). Together with empirical data [reviewed in (Marchetti et al. 2018b)], this model formed the basis for the recent revision of TG 488, which recommends the $28+28 \mathrm{~d}$ design for assessment of germ cell mutagenicity (OECD 2020).

The revision of TG 488 pertaining to germ cell study designs further proposes the $28+28 \mathrm{~d}$ design as a common protocol for simultaneously assessing mutagenicity in somatic tissues and germ cells of the same animals. However, additional data are urgently needed to evaluate the impact of the $28+28 \mathrm{~d}$ design on the detection of mutations in rapidly proliferating tissues. Here, we investigated the 
influence of the sampling time on MF in BM (i.e., a rapidly proliferating tissue) of MutaMouse animals exposed to four established mutagens with greatly different mutagenic responses: benzo(a)pyrene (BaP) (Lemieux et al. 2011); procarbazine (PRC) (Maurice et al. 2019; Suzuki et al. 1999), isopropyl methanesulfonate (iPMS) (Coffing et al. 2015; Itoh et al. 2016); and triethylenemelamine (TEM) (Maurice et al. 2018). Each chemical was tested using a 28 days repeated-dose treatment and at least three doses alongside concurrent controls. BM was collected on post-exposure days $+3,+28,+42$ or +70 . MF were determined using the lac $Z$ assay and the Benchmark Dose (BMD) approach used to evaluate the effect of sampling times.

\section{Materials and methods}

\section{Animals}

The use of mice in these studies was approved by the Health Canada Ottawa Animal Care Committee. All animal exposures and handling were conducted in accordance with the Guidelines of the Canadian Council on Animal Care (CCAC) described in the CCAC Guide to the Care and Use of Experimental Animals (CCAC 1993). MutaMouse males for these experiments were generated from an in-house colony of animals each harboring 29 tandem copies of a recombinant $\lambda$ gt10 phage shuttle vector on each copy of chromosome 3 (Shwed et al. 2010). Mice were maintained under a $12 \mathrm{~h}$ light/ $12 \mathrm{~h}$ dark photoperiod at room temperature of $21{ }^{\circ} \mathrm{C}$ and relative humidity of $50 \%$ with access to water and food ad libitum throughout the acclimation and experimental periods. Adult MutaMouse males, 9-14 weeks of age at the beginning of the exposure, were randomly assigned to dose groups; typically, four mice for the control group, and eight mice per treatment group per time point. Animals were individually housed in microVENT ventilated racks (Allentown, Allentown, NJ).

\section{Chemicals and exposures}

BaP (CAS 50-32-8), PRC (CAS 366-70-1) and PMS (CAS 926-06-7) were purchased from Sigma-Aldrich Canada Co. (Oakville ON Canada). TEM (CAS 51-18-3) was bought from Synchem Ug and Co.KG (Felsberg, Altenburg, Germany). BaP and iPMS were dissolved in olive oil (SigmaAldrich, Oakville ON Canada), while PRC and TEM were prepared with phosphate-buffered saline without calcium and magnesium (PBS; Corning cellgro, Manassas, VA, USA).

For each chemical, the top dose was selected based on pilot dose range-finding studies to exclude doses that induced excessive morbidity or toxicity, such as approaching a $20 \%$ decrease in body weight (bw). Dose levels for the main studies were: $0,12.5,25,50$ and $100 \mathrm{mg} / \mathrm{kg}$ bw for BaP; $0,6.25,12.5$ and $25 \mathrm{mg} / \mathrm{kg}$ bw for PRC; 0, 1.25, 2.5 and $5 \mathrm{mg} / \mathrm{kg}$ bw for iPMS; and $0,1,2$, and $5 \mathrm{mg} / \mathrm{kg}$ bw for TEM. Dissolved chemicals and vehicle controls were administered daily by oral gavage in a volume of $5 \mathrm{~mL} / \mathrm{kg}$ bw for 28 consecutive days according to TG 488 . Animals were euthanized by cardiac puncture under isoflurane anesthesia at $+3 \mathrm{~d},+28 \mathrm{~d},+42 \mathrm{~d}$ or $+70 \mathrm{~d}$ post exposure. The femurs were removed and BM was flushed out in $1 \mathrm{~mL}$ of PBS and centrifuged at 10,000 rpm for $30 \mathrm{~s}$; pellets were resuspended in $100 \mu \mathrm{L}$ of PBS, and frozen in liquid nitrogen and stored at $-80{ }^{\circ} \mathrm{C}$ until use.

The four sampling times for $\mathrm{BaP}$ represent three experiments that were conducted at different times. The first experiment included doses up to $50 \mathrm{mg} / \mathrm{kg} \mathrm{BaP}$ and did not include the $+28 \mathrm{~d}$ sampling time; the second experiment used only the $100 \mathrm{mg} / \mathrm{kg} \mathrm{BaP}$ dose and, as in the first one, did not include the $+28 \mathrm{~d}$ sampling time; and, the third experiment included all doses with just the $+28 \mathrm{~d}$ sampling time. Each experiment had its own concurrent controls. Conversely, the four sampling times for PRC, iPMS and TEM were conducted as parts of single experiments where all animals were treated at the same time and randomly allocated to one of the four sampling times. In these experiments, only four control animals were used at each sampling time in an effort to adhere to 3 Rs principles, and with the intention of combining all controls at the four sampling times into a single group for statistical analyses.

\section{DNA extraction}

Total genomic DNA from BM samples was extracted as previously described (Gingerich et al. 2014). Briefly, $50 \mu \mathrm{L}$ of thawed BM was added into $5 \mathrm{~mL}$ lysis buffer [10 $\mathrm{mM}$ EDTA, $100 \mathrm{mM} \mathrm{NaCl}, 10 \mathrm{mM}$ Tris-HCl, $\mathrm{pH}$ 7.6, $1 \%$ sodium dodecyl sulfate (w/v) and $1 \mathrm{mg} / \mathrm{mL}$ Proteinase $\mathrm{K}$ (Invitrogen, Burlington, Canada)], and digested at $37{ }^{\circ} \mathrm{C}$ overnight with gentle shaking. Genomic DNA was isolated using the phenol/chloroform extraction procedure. Precipitated DNA was dissolved in $30-75 \mu \mathrm{L}$ TE buffer $(10 \mathrm{mM}$ Tris $\mathrm{pH}$ 7.6, $0.1 \mathrm{mM}$ EDTA) and stored at $4{ }^{\circ} \mathrm{C}$. The quantity and quality of DNA were assessed using a NanoDrop spectrophotometer (Thermo Scientific Canada, Ottawa, Canada).

\section{Mutant frequency analysis}

BM samples used in these studies are from the same animals whose MF were previously reported for PRC (Maurice et al. 2019), TEM (Maurice et al. 2018), and BaP (Beal et al. 2015). However, except for the high dose of $\mathrm{BaP}$ at $28+3 \mathrm{~d}$, where no DNA was available, new DNA isolations 
and lac $Z$ assays were conducted to generate the MF data reported here.

$\lambda \mathrm{gt10}$ phage vectors in genomic DNA were excised using commercial packaging extract kits (Agilent technology, Santa Clara, CA, USA) according to the manufacturer's instructions. Transgene MF was determined using the phenyl $\beta$-D-galactopyranoside (P-gal)-positive selection assay (Lambert et al. 2005; Vijg and Douglas 1996). Briefly, packaged phage particles were adsorbed to E. coli host cells (lacZ ${ }^{-} / \mathrm{galE}^{-}$); the host cells were mixed with selective LB top agar containing $0.3 \%$ phenyl $\beta$-D-galactoside (P-gal; Sigma-Aldrich, Oakville ON Canada) and then plated. Concurrently, a small proportion of bacteria with adsorbed phage particles were mixed with nonselective LB top agar to estimate total plaque-forming units (pfu). All plates were incubated overnight at $37{ }^{\circ} \mathrm{C}$. A minimum of 125,000 total pfu were scored for each animal. MF was expressed as the ratio of mutant plaques to total pfu.

\section{Statistical analyses}

Except in a few cases, multiple lac $Z$ packaging reactions were needed to reach the minimum number of pfu for each animal. Thus, to identify outlier replicates, we first analyzed MF from each reaction using a generalized linear mixed model (GLMM) with a binomial error distribution in R software. This model accounts for the dose effect, and also for random differences between individuals. Observations were identified as outliers whenever the model residuals were greater than a cut-off point; typically, $>3$ standard deviations of the mean (Gelman and Hill 2007). The most extreme outliers were removed, and the analysis repeated until all outlier replicates were removed. In total, 18 replicates out of $960(1.8 \%)$ were removed. The data were then collapsed by animal and analyses conducted again to identify individual animal outliers. This resulted in the elimination of three animals out of $461(0.65 \%)$. All three animals were controls in the BaP experiment. Estimated MF were obtained using generalized linear models in the R software with the quasibinomial distribution. Pairwise comparisons were conducted using the doBy R library (Højsgaard and Halekoh
2018) and these estimates were then back transformed. Here, the delta method was employed to approximate the backtransformed standard errors of the estimated MF. Finally, a Holm-Sidak correction was applied to adjust p-values for multiple comparisons.

\section{Dose-response modelling and benchmark dose (BMD) determination}

The BMD combined-covariate approach was employed to examine the influence of sampling time on the potency (i.e., BMD) of each tested chemical (Wills et al. 2016). BMD analyses were conducted using PROAST in R (version 67.1, https://rivm.nl/en/proast). Following the recommendation of White et al. (2020), the benchmark response (BMR) was set to $50 \%$. To ensure consistency of the analyses across the tested substances, the dose-response data were analysed using a five parameter exponential model. BMD-covariate analyses often assume that some model parameters (e.g., $c$ and $d$ for maximum response and log-steepness after axis scaling) are constant across covariate sub-groups (Wills et al. 2017); this is consistent with the work of (Slob and Setzer 2014). The AIC (Akaike Information Criterion) was used for model selection, and post-hoc analyses statistically evaluated the effect of sampling time on any retained parameter. The upper and lower confidence limits of the BMD values (i.e., the BMDL and BMDU) were used to statistically evaluate the effect of sampling time.

\section{Results}

\section{Analyses of mutant frequencies in control animals by age}

A total of 84 control animals were used in these studies. Table 1 shows the lac $Z$ MF by sampling time across the four chemical experiments for the control mice. An average of 339,608 $\pm 171,139$ (mean $\pm \mathrm{SD}$ ) pfu per control animal was analyzed. We found that MF $\left(\times 10^{-5}\right)$ tended to increase with sampling time, with $\mathrm{MF}$ ( \pm standard deviation)
Table 1 LacZ mutant frequencies in the bone marrow of MutaMouse control mice by sampling time

\begin{tabular}{llllll}
\hline $\begin{array}{l}\text { Sampling time } \\
\text { (days) }\end{array}$ & No. of animals & No. of Mutants & No. of $\mathrm{pfu}^{\mathrm{a}}$ & $\begin{array}{l}\text { Average }^{\mathrm{b}} \\
\mathrm{MF} \times 10^{-5}\end{array}$ & $\mathrm{SD}^{\mathrm{b}}$ \\
\hline $28+3$ & 22 & 372 & $8,254,339$ & 4.3 & 1.9 \\
$28+28$ & 17 & 240 & $4,444,173$ & 5.4 & 1.7 \\
$28+42$ & 23 & 436 & $7,770,245$ & $5.8 *$ & 2.8 \\
$28+70$ & 22 & 434 & $8,058,374$ & 5.7 & 2.3 \\
\hline
\end{tabular}

${ }^{a}$ Plaque forming units (pfu)

${ }^{\mathrm{b}}$ Average mutant frequency (MF) and standard deviation (SD) of the arithmetic mean of individual animals ${ }^{*} p<0.03$ vs $28+3 \mathrm{~d}$ sampling time 
of $4.3 \pm 1.9,5.4 \pm 1.7,5.8 \pm 2.8$ and $5.7 \pm 2.3$ at $28+3 \mathrm{~d}$, $28+28 \mathrm{~d}, 28+42 \mathrm{~d}$ and $28+70 \mathrm{~d}$, respectively. Furthermore, the MF at $28+42 \mathrm{~d}$ was significantly higher $(p<0.03)$ than that observed at $28+3 \mathrm{~d}$. A longer sampling time necessarily results in older animals; however, the age of the animals at the beginning of each experiment also varied. Therefore, rather than using the sampling time as a proxy for chronological age, we also considered the litter's day of birth with respect to euthanasia to better analyze the association between MF and age. Because we could not separate the animals into four groups with no age overlap based on the day of birth, MF were analyzed by quartile. This analysis showed a clearer age effect with MF increasing by quartile (Fig. 1). In fact, median $\mathrm{MF} \times 10^{-5}$ were $4.3,4.5,4.7$ and 6.2 for the 1st, 2nd, 3rd and 4th quartile, respectively. The difference between the 1st and 4th quartile was at the borderline of significance $(p=0.06)$. Figure 1 also shows that controls from $28+3 \mathrm{~d}$ and $28+28 \mathrm{~d}$ represented 39 of the 42 animals in the first two quartiles, and controls from $28+42 \mathrm{~d}$ and $28+70 \mathrm{~d}$ represented all of the animals in the last two quartiles.

These results did not support the merging of the controls from all four sampling times within each experiment, as it was originally planned in an effort to reduce the number of animals used and adhere to the 3 Rs principles. Instead, in each experiment, we merged controls at $28+3 \mathrm{~d}$ and $28+28 \mathrm{~d}$ to analyze the chemical response at these two timepoints and merged controls at $28+42 \mathrm{~d}$ and $28+70 \mathrm{~d}$ to analyze the chemical response at the two later timepoints.
Fig. 1 Mutant frequencies in control animals by age. The top panel shows the median mutant frequencies in control animals by age quartile. Median mutant frequencies were $4.3,4.5,4.7$ and $6.2 \times 10^{-5}$ for $1 \mathrm{st}, 2 \mathrm{nd}, 3 \mathrm{rd}$, and 4 th quartile, respectively. There is a borderline significant trend $(p=0.06)$ for an age effect. The bottom panel shows the distribution of control animals from the four sampling times among quartiles
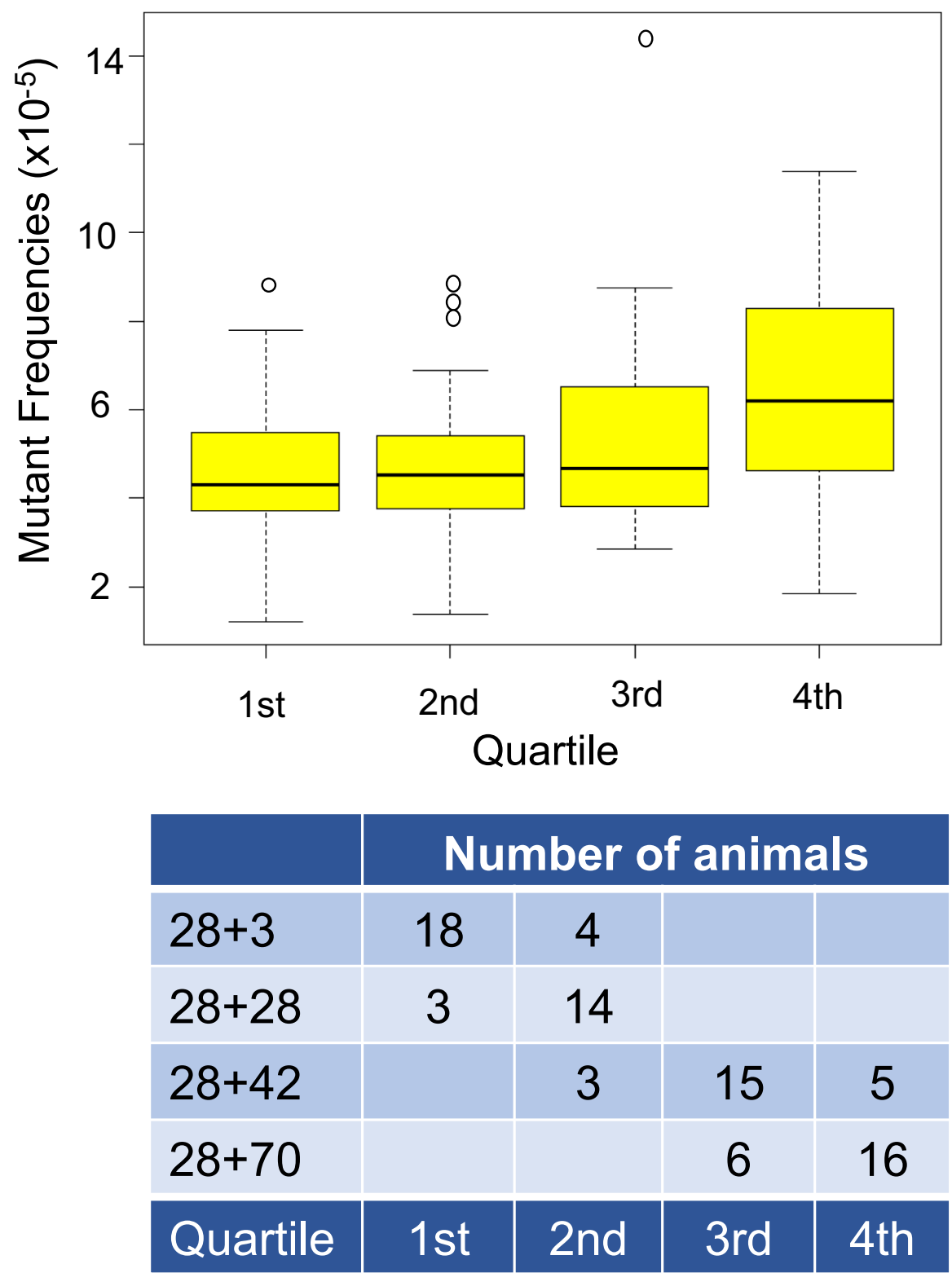


\section{Qualitative analyses: effect of the sampling time on mutant frequencies in bone marrow}

The lacZ MF measured at the four sampling times in the BM of MutaMouse males exposed to $\mathrm{BaP}$ are shown in Table 2 and graphically in Fig. 2a. BaP induced statistically significant dose-dependent increases in MF that reached a maximum of $1204.1 \times 10^{-5}$ for the high dose group of $100 \mathrm{mg} /$ $\mathrm{kg}$ bw/day at $28+28 \mathrm{~d}$. Fold changes for the BaP high dose group were between 163 and 274 depending on sampling time, while at the low dose of $12.5 \mathrm{mg} / \mathrm{kg}$ bw/day they were between 14 and 27. Regardless of sampling time, all four doses of $\mathrm{BaP}$ induced statistically significant increases in MF with respect to concurrent controls $(p<0.0001)$. Thus, analyses of MF in BM after BaP exposure produced qualitatively similar results at all sampling times investigated for all four doses tested.

The lacZ MF measured at the four sampling times in the BM of MutaMouse males exposed to PRC are shown in Table 3 and graphically in Fig. 2b. As for BaP, PRC induced statistically significant dose-dependent increases in MF that reached a maximum of $42.0 \times 10^{-5}$ for the high dose group of $25 \mathrm{mg} / \mathrm{kg}$ bw/day at $28+3 \mathrm{~d}$. Fold changes for the high dose groups were between 4.5 and 6.5 depending on sampling time, while at the low dose of $6.25 \mathrm{mg} / \mathrm{kg}$ bw/day they were between 1.7 and 2.5. For PRC, the high and middle dose group $(12.5 \mathrm{mg} / \mathrm{kg}$ bw/day) induced statistically significant increases in MF with respect to concurrent controls $(p<0.0001)$ at all four sampling times. For the low dose group, a statistically significant increase in MF with respect to concurrent controls was observed at all sampling times except $28+70 \mathrm{~d}(p=0.34)$. Except for this last result, analyses of MF in BM after PRC exposure produced qualitatively similar results at all sampling times investigated.

The lacZ MF measured at the four sampling times in the $\mathrm{BM}$ of MutaMouse males exposed to iPMS are shown in Table 4 and graphically in Fig. 2c. iPMS induced a consistent statistically significant $(p<0.001)$ increase in MF across sampling times, but only for the high dose group of $5 \mathrm{mg} / \mathrm{kg}$ bw/day. Fold-changes for the high dose group were between 4.7 and 2.9 depending on sampling time, with the MF reaching a maximum of $21.8 \times 10^{-5}$ at $28+3 \mathrm{~d}$. The low dose of $1.25 \mathrm{mg} / \mathrm{kg}$ bw/day did not statistically increase MF with respect to controls at any of the sampling times investigated,
Table 2 LacZ mutant frequencies in the bone marrow of MutaMouse mice exposed to benzo(a)pyrene and collected at various sampling times

\begin{tabular}{|c|c|c|c|c|c|c|c|}
\hline $\begin{array}{l}\text { Sampling } \\
\text { time (days) }\end{array}$ & $\begin{array}{l}\text { Dose } \\
(\mathrm{mg} / \mathrm{kg} / \\
\text { day) }\end{array}$ & No. of animals & No. of Mutants & No. of $\mathrm{pfu}^{\mathrm{a}}$ & $\begin{array}{l}\text { Average }^{\mathrm{b}} \\
\mathrm{MF} \times 10^{-5}\end{array}$ & $\mathrm{SD}^{\mathrm{b}}$ & $p$ value $^{\mathrm{c}}$ \\
\hline \multirow[t]{5}{*}{$28+3^{\mathrm{d}}$} & 0 & 18 & 278 & $6,353,978$ & 4.4 & 3.1 & - \\
\hline & 12.5 & 4 & 1,193 & $1,061,591$ & 116.7 & 30.1 & $1.5 \mathrm{E}-11$ \\
\hline & 25 & 6 & 3,291 & $1,481,392$ & 226.4 & 55.6 & $1.2 \mathrm{E}-15$ \\
\hline & 50 & 6 & 5,400 & $1,238,524$ & 445.8 & 82.5 & $<1.0 \mathrm{E}-16$ \\
\hline & 100 & 6 & 18,261 & $2,453,689$ & 716.7 & 128.2 & $<1.0 \mathrm{E}-16$ \\
\hline \multirow[t]{5}{*}{$28+28^{\mathrm{d}}$} & 0 & 18 & 278 & $6,353,978$ & 4.4 & 3.1 & - \\
\hline & 12.5 & 8 & 1,830 & $1,583,440$ & 114.4 & 29.3 & $1.3 \mathrm{E}-13$ \\
\hline & 25 & 8 & 4,995 & $1,622,704$ & 308.8 & 54.0 & $<1.0 \mathrm{E}-16$ \\
\hline & 50 & 8 & 8,663 & $1,445,276$ & 598.2 & 139.0 & $<1.0 \mathrm{E}-16$ \\
\hline & 100 & 6 & 13,354 & $1,088,927$ & 1204.1 & 177.1 & $<1.0 \mathrm{E}-16$ \\
\hline \multirow[t]{5}{*}{$28+42^{\mathrm{e}}$} & 0 & 21 & 451 & $8,433,262$ & 5.1 & 2.0 & - \\
\hline & 12.5 & 6 & 816 & $1,218,973$ & 68.2 & 30.4 & $5.0 \mathrm{E}-7$ \\
\hline & 25 & 6 & 2,321 & $1,160,993$ & 191.5 & 49.1 & 2.0E-12 \\
\hline & 50 & 6 & 4,452 & $1,101,187$ & 408.8 & 93.3 & $1.8 E-13$ \\
\hline & 100 & 6 & 18,848 & $2,308,731$ & 885.8 & 272.1 & $<1.0 \mathrm{E}-16$ \\
\hline \multirow[t]{5}{*}{$28+70^{\mathrm{e}}$} & 0 & 21 & 451 & $8,433,262$ & 5.1 & 2.0 & - \\
\hline & 12.5 & 5 & 2,330 & $2,968,083$ & 78.9 & 17.1 & $5.2 \mathrm{E}-11$ \\
\hline & 25 & 6 & 5,978 & $2,831,739$ & 218.0 & 40.9 & $8.9 E-16$ \\
\hline & 50 & 5 & 11,755 & $2,223,579$ & 547.8 & 96.7 & $<1.0 \mathrm{E}-16$ \\
\hline & 100 & 6 & 18,140 & $1,798,146$ & 1066.3 & 204.1 & $<1.0 \mathrm{E}-16$ \\
\hline
\end{tabular}

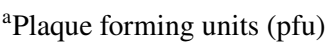

${ }^{\mathrm{b}}$ Average mutant frequency (MF) and standard deviation (SD) of the arithmetic mean of individual animals ${ }^{c}$ vs controls (Bold $p$ values indicate statistical significance after Holm-Sidak correction for multiple comparisons)

${ }^{\mathrm{d}}$ Combined controls from $28+3 \mathrm{~d}$ and $28+28 \mathrm{~d}$ sampling times

${ }^{\mathrm{e}}$ Combined controls from $28+42 \mathrm{~d}$ and $28+70 \mathrm{~d}$ sampling times 


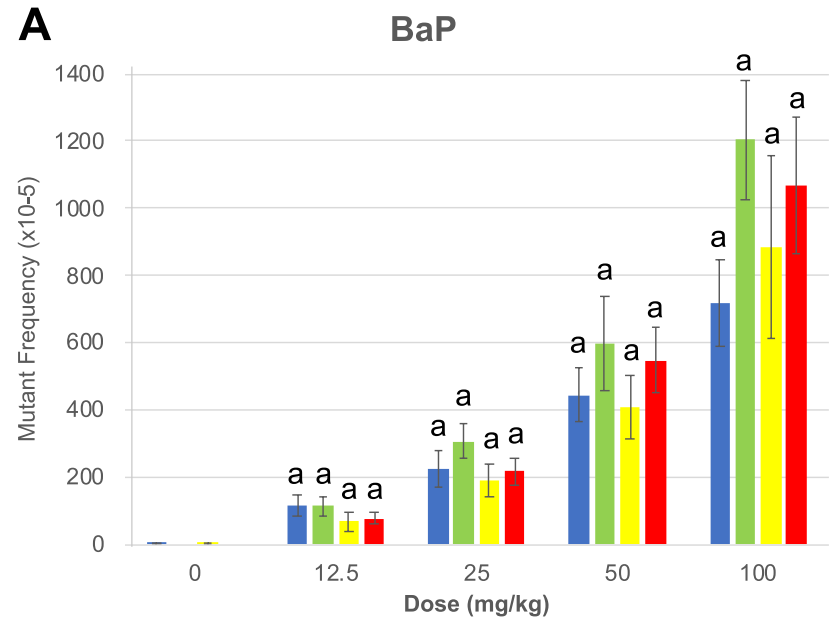

C

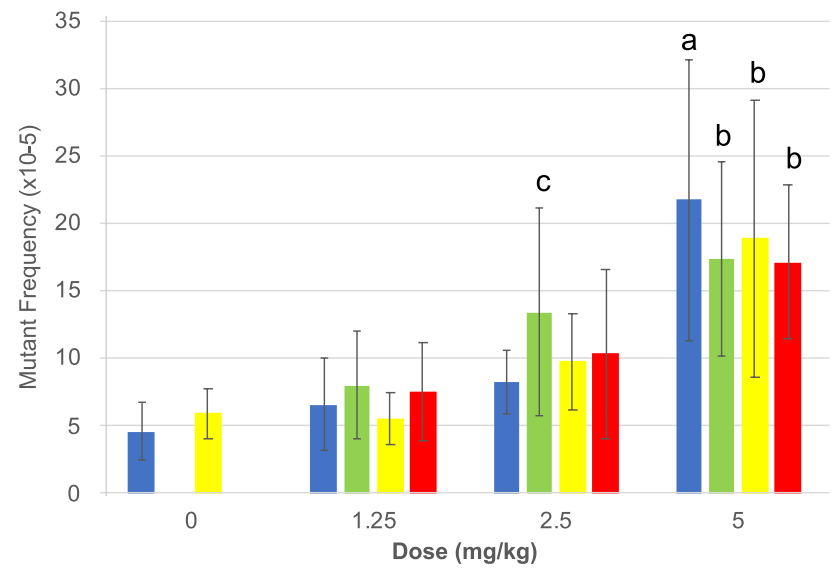

Fig. 2 Mutant frequencies in the bone marrow of MutaMouse males at the various sampling times. The frequencies of lac $Z$ mutants in the bone marrow of MutaMouse males exposed to benzo(a)pyrene a, procarbazine $\mathbf{b}$, isopropyl methanesulfonate $\mathbf{c}$ and triethylenemelamine $\mathbf{d}$ were evaluated at $28+3 \mathrm{~d}$ (blue), $28+28 \mathrm{~d}$ (green), $28+42 \mathrm{~d}$ (yellow) and $28+70 \mathrm{~d}$ (red). For each dose group, the mean \pm standard deviation is shown. In each experiment, controls at $28+3 \mathrm{~d}$ and $28+28 \mathrm{~d}$ were merged into a single control group (blue bar) that was used to analyze the dose-response at these two time points. Similarly,

while the middle dose of $2.5 \mathrm{mg} / \mathrm{kg}$ bw/day produced a statistically significant increase in MF of $13.4 \times 10^{-5}$ only at $28+28$ d. Overall, the four sampling times produced qualitatively similar results.

The lacZ MF measured at the four sampling times in the BM of MutaMouse males exposed to TEM are shown in Table 5 and graphically in Fig. 2d. Based on previous results (Maurice et al. 2018), TEM was expected to induce the lowest fold-increase in MF among the four mutagens investigated. Indeed, only the high dose of $5 \mathrm{mg} / \mathrm{kg}$ bw/day induced a statistically significant $(p<0.05)$ increase in MF at the first two sampling times, while no statistically significant increase was seen at the later two sampling times.
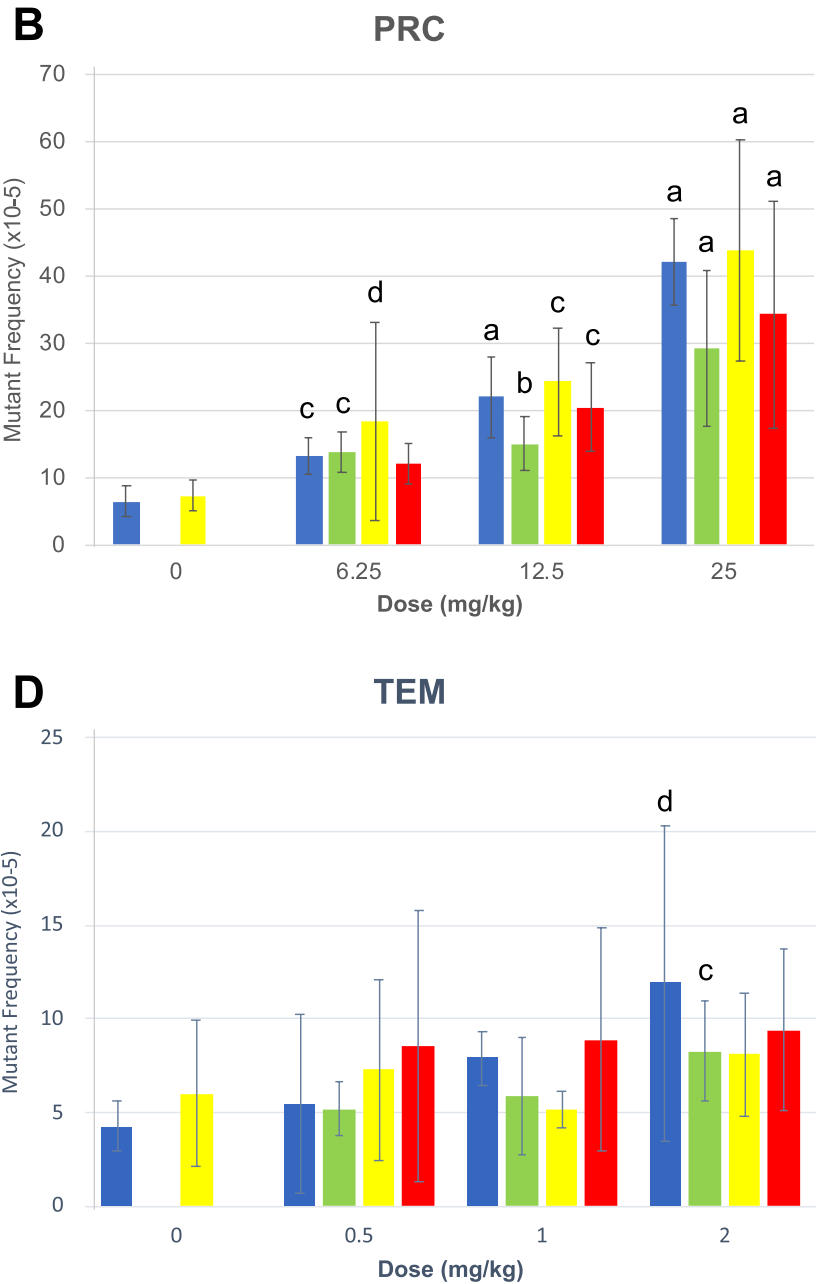

controls at $28+42 \mathrm{~d}$ and $28+70 \mathrm{~d}$ were merged into a single control group (yellow bar) that was used to analyze the dose-response at these two time points. Note that each panel uses a different $Y$ axis and that control bars for the $\mathrm{BaP}$ experiment are difficult to see because of the magnitude of the response at the high dose. Statistical results with respect to concurrent controls are presented for each dose and sampling time. The level of significance is indicated as follows: $a=p<0.0001 ; b=p<0.001 ; c=p<0.01$; and, $d=p<0.05$ (color figure online)

Fold-changes at $28+3 \mathrm{~d}$ and $28+28 \mathrm{~d}$ were 2.8 and 1.9 , respectively. Furthermore, the middle and low TEM doses did not significantly increase MF at any of the four sampling times investigated. Thus, the results with TEM suggest that the response at the first two sampling times was qualitatively different than that observed at the two later sampling times.

As summarized in Table 6, the statistical analyses just described indicated that the sampling time had little impact on the qualitative analyses of the overall response for the three chemicals that elicited strong responses. However, the results with TEM suggest that when the mutagenic response is weak, sampling times greater than 28 days may reduce the chance of detecting a significant effect. 
Table 3 LacZ mutant frequencies in the bone marrow of MutaMouse mice exposed to procarbazine and collected at various sampling times
Table 4 LacZ mutant frequencies in the bone marrow of MutaMouse mice exposed to isopropyl methanesulfonate and collected at various sampling times

\begin{tabular}{llllllrl}
\hline $\begin{array}{l}\text { Sampling } \\
\text { time (days) }\end{array}$ & $\begin{array}{l}\text { Dose }(\mathrm{mg} / \\
\mathrm{kg} / \text { day })\end{array}$ & $\begin{array}{l}\text { No. of } \\
\text { animals }\end{array}$ & No. of Mutants & $\begin{array}{l}\text { No. of pfu } \\
\text { a }\end{array}$ & $\begin{array}{l}\text { Average }_{\mathrm{b}} \\
\text { MF } \times 10^{-5}\end{array}$ & SD $^{\mathrm{b}}$ & $p$ value $^{\mathrm{c}}$ \\
\hline $28+3^{\mathrm{d}}$ & 0 & 7 & 140 & $2,164,269$ & 6.4 & 2.3 & - \\
& 6.25 & 8 & 380 & $2,909,145$ & 13.2 & 2.7 & $\mathbf{0 . 0 0 3 4}$ \\
& 12.5 & 8 & 673 & $3,108,736$ & 21.9 & 6.0 & $\mathbf{1 . 1 E}-\mathbf{6}$ \\
& 25 & 8 & 1465 & $3,467,239$ & 42.0 & 6.5 & $\mathbf{7 . 0 E}-\mathbf{1 1}$ \\
$28+28^{\mathrm{d}}$ & 0 & 7 & 140 & $2,164,269$ & 6.4 & 2.3 & - \\
& 6.25 & 8 & 188 & $1,384,324$ & 13.7 & 3.1 & $\mathbf{0 . 0 0 5 2}$ \\
& 12.5 & 8 & 241 & $1,544,345$ & 15.0 & 4.0 & $\mathbf{0 . 0 0 0 5}$ \\
& 25 & 7 & 385 & $1,420,095$ & 29.1 & 11.6 & $\mathbf{1 . 2 E}-\mathbf{7}$ \\
$28+42^{\mathrm{e}}$ & 0 & 8 & 107 & $1,518,994$ & 7.2 & 2.3 & - \\
& 6.25 & 8 & 298 & $1,427,597$ & 18.3 & 14.8 & $\mathbf{0 . 0 2 2 6}$ \\
& 12.5 & 7 & 336 & $1,414,285$ & 24.3 & 8.0 & $\mathbf{0 . 0 0 8 7}$ \\
& 25 & 7 & 669 & $1,501,046$ & 43.8 & 16.3 & $\mathbf{4 . 0 E}-\mathbf{5}$ \\
& 0 & 8 & 107 & $1,518,994$ & 7.2 & 2.3 & - \\
& 6.25 & 7 & 153 & $1,283,787$ & 12.1 & 3.0 & 0.3385 \\
& 12.5 & 7 & 254 & $1,268,714$ & 20.4 & 6.6 & $\mathbf{0 . 0 0 6 4}$ \\
& 25 & 8 & 538 & $1,649,728$ & 34.2 & 16.8 & $\mathbf{3 . 1 E}-\mathbf{5}$ \\
\hline
\end{tabular}

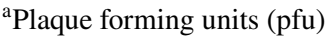

${ }^{\mathrm{b}}$ Average mutant frequency (MF) and standard deviation (SD) of the arithmetic mean of individual animals ${ }^{c}$ vs controls (Bold $p$ values indicate statistical significance after Holm-Sidak correction for multiple comparisons)

${ }^{\mathrm{d}}$ Combined controls from $28+3 \mathrm{~d}$ and $28+28 \mathrm{~d}$ sampling times

${ }^{\mathrm{e}}$ Combined controls from $28+42 \mathrm{~d}$ and $28+70 \mathrm{~d}$ sampling times

\begin{tabular}{|c|c|c|c|c|c|c|c|}
\hline $\begin{array}{l}\text { Sampling } \\
\text { time (days) }\end{array}$ & $\begin{array}{l}\text { Dose }(\mathrm{mg} / \\
\mathrm{kg} / \text { day) }\end{array}$ & $\begin{array}{l}\text { No. of } \\
\text { animals }\end{array}$ & No. of Mutants & No. of $\mathrm{pfu}^{\mathrm{a}}$ & $\begin{array}{l}\text { Average }^{\mathrm{b}} \\
\mathrm{MF} \times 10^{-5}\end{array}$ & $\mathrm{SD}^{\mathrm{b}}$ & $p$ value \\
\hline \multirow[t]{4}{*}{$28+3^{\mathrm{d}}$} & 0 & 8 & 115 & $2,308,895$ & 4.6 & 2.1 & - \\
\hline & 1.25 & 6 & 107 & $1,603,984$ & 6.6 & 3.4 & 0.7581 \\
\hline & 2.5 & 8 & 172 & $2,035,545$ & 8.3 & 2.3 & 0.2247 \\
\hline & 5 & 8 & 457 & $2,131,302$ & 21.8 & 10.4 & $1.2 \mathrm{E}-5$ \\
\hline \multirow[t]{4}{*}{$28+28^{d}$} & 0 & 8 & 115 & $2,308,895$ & 4.6 & 2.1 & - \\
\hline & 1.25 & 8 & 108 & $1,408,166$ & 8.0 & 3.9 & 0.4028 \\
\hline & 2.5 & 6 & 176 & $1,261,221$ & 13.4 & 7.7 & 0.0019 \\
\hline & 5 & 8 & 267 & $1,513,531$ & 17.3 & 7.2 & 0.0001 \\
\hline \multirow[t]{4}{*}{$28+42^{\mathrm{e}}$} & 0 & 8 & 90 & $1,453,394$ & 5.9 & 1.9 & - \\
\hline & 1.25 & 8 & 77 & $1,362,941$ & 5.6 & 2.0 & 0.9892 \\
\hline & 2.5 & 8 & 148 & $1,508,725$ & 9.8 & 3.5 & 0.2955 \\
\hline & 5 & 8 & 340 & $1,591,724$ & 18.9 & 10.2 & 0.0001 \\
\hline \multirow[t]{4}{*}{$28+70^{\mathrm{e}}$} & 0 & 8 & 90 & $1,453,394$ & 5.9 & 1.9 & - \\
\hline & 1.25 & 8 & 149 & $2,071,328$ & 7.5 & 3.6 & 0.9424 \\
\hline & 2.5 & 8 & 238 & $1,987,337$ & 10.4 & 6.3 & 0.0648 \\
\hline & 5 & 8 & 402 & $2,158,305$ & 17.2 & 5.7 & 0.0006 \\
\hline
\end{tabular}

${ }^{\text {a }}$ Plaque forming units (pfu)

${ }^{\mathrm{b}}$ Average mutant frequency (MF) and standard deviation (SD) of the arithmetic mean of individual animals ${ }^{c}$ vs controls (Bold $P$-values indicate statistical significance after Holm-Sidak correction for multiple comparisons)

${ }^{\mathrm{d}}$ Combined controls from $28+3 \mathrm{~d}$ and $28+28 \mathrm{~d}$ sampling times

${ }^{\mathrm{e}}$ Combined controls from $28+42 \mathrm{~d}$ and $28+70 \mathrm{~d}$ sampling times 
Table 5 LacZ mutant frequencies in the bone marrow of MutaMouse mice exposed to triethylenemelamine and collected at various sampling times

\begin{tabular}{|c|c|c|c|c|c|c|c|}
\hline $\begin{array}{l}\text { Sampling } \\
\text { time (days) }\end{array}$ & $\begin{array}{l}\text { Dose }(\mathrm{mg} / \\
\mathrm{kg} / \text { day) }\end{array}$ & $\begin{array}{l}\text { No. of } \\
\text { animals }\end{array}$ & No. of Mutants & No. of $\mathrm{pfu}^{\mathrm{a}}$ & $\begin{array}{l}\text { Average }^{\mathrm{b}} \\
\mathrm{MF} \times 10^{-5}\end{array}$ & $\mathrm{SD}^{\mathrm{b}}$ & $p$ value $^{\mathrm{c}}$ \\
\hline \multirow[t]{4}{*}{$28+3^{\mathrm{d}}$} & 0 & 6 & 79 & $1,871,370$ & 4.3 & 1.3 & - \\
\hline & 0.5 & 8 & 133 & $2,314,695$ & 5.5 & 4.8 & 0.8400 \\
\hline & 1 & 6 & 151 & $1,947,742$ & 7.9 & 1.4 & 0.3656 \\
\hline & 2 & 7 & 293 & $2,425,691$ & 11.9 & 8.4 & 0.0246 \\
\hline \multirow[t]{4}{*}{$28+28^{\mathrm{d}}$} & 0 & 6 & 79 & $1,871,370$ & 4.3 & 1.3 & - \\
\hline & 0.5 & 8 & 139 & $2,669,883$ & 5.2 & 1.4 & 0.7364 \\
\hline & 1 & 8 & 119 & $1,957,186$ & 5.9 & 3.2 & 0.3337 \\
\hline & 2 & 8 & 180 & $2,036,376$ & 8.3 & 2.6 & 0.0059 \\
\hline \multirow[t]{4}{*}{$28+42^{\mathrm{e}}$} & 0 & 8 & 249 & $4,422,969$ & 6.0 & 3.9 & - \\
\hline & 0.5 & 8 & 262 & $3,847,940$ & 7.3 & 4.8 & 0.8592 \\
\hline & 1 & 8 & 232 & $4,329,862$ & 5.2 & 1.0 & 0.9971 \\
\hline & 2 & 8 & 353 & $4,219,862$ & 8.1 & 3.3 & 0.3230 \\
\hline \multirow[t]{4}{*}{$28+70^{\mathrm{e}}$} & 0 & 8 & 249 & $4,422,969$ & 6.0 & 3.9 & - \\
\hline & 0.5 & 8 & 256 & $3,831,039$ & 8.6 & 7.2 & 0.9454 \\
\hline & 1 & 8 & 277 & $3,102,774$ & 8.9 & 5.9 & 0.4502 \\
\hline & 2 & 8 & 411 & $4,558,813$ & 9.4 & 4.3 & 0.3609 \\
\hline
\end{tabular}

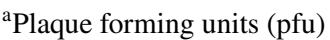

${ }^{\mathrm{b}}$ Average mutant frequency (MF) and standard deviation (SD) of the arithmetic mean of individual animals ${ }^{c}$ vs controls (Bold $p$ values indicate statistical significance after Holm-Sidak correction for multiple comparisons)

${ }^{\mathrm{d}}$ Combined controls from $28+3 \mathrm{~d}$ and $28+28 \mathrm{~d}$ sampling times

${ }^{\mathrm{e}}$ Combined controls from $28+42 \mathrm{~d}$ and $28+70 \mathrm{~d}$ sampling times

\begin{tabular}{|c|c|c|c|c|}
\hline \multirow[t]{2}{*}{ Chemical } & \multicolumn{4}{|l|}{ Sampling time } \\
\hline & $28+3 d$ & $28+28 d$ & $28+42 d$ & $28+70 d$ \\
\hline Benzo(a)pyrene & $\mathrm{L}, \mathrm{M}, \mathrm{MH}, \mathrm{H}$ & $\mathrm{L}, \mathrm{M}, \mathrm{MH}, \mathrm{H}$ & $\mathrm{L}, \mathrm{M}, \mathrm{MH}, \mathrm{H}$ & $\mathrm{L}, \mathrm{M}, \mathrm{MH}, \mathrm{H}$ \\
\hline Procarbazine & $\mathrm{L}, \mathrm{M}, \mathrm{H}$ & $\mathrm{L}, \mathrm{M}, \mathrm{H}$ & $\mathrm{L}, \mathrm{M}, \mathrm{H}$ & $\mathrm{M}, \mathrm{H}$ \\
\hline Isopropyl methanesulfonate & $\mathrm{H}$ & $\mathrm{M}, \mathrm{H}$ & $\mathrm{H}$ & $\mathrm{H}$ \\
\hline Triethylenemelamine & $\mathrm{H}$ & $\mathrm{H}$ & - & - \\
\hline
\end{tabular}

$L$ low, $M$ medium, $M H$ medium high, $H$ high
Table 6 Summary of doses with statistically significant increases with respect to concurrent controls by sampling time

\section{Quantitative analyses: BMD modelling to examine the effect of sampling time on mutant mutagenic potency of each tested substance}

Next, we used the BMD combined-covariate approach to determine if the sampling time had a significant effect on mutagenic potency. For each tested chemical, the AIC value was used to select the appropriate model with which to evaluate the effect of sampling time on compound-specific BMDs. Estimates of parameters retained in models selected using the AIC did not indicate any covariatedependence for parameters $c$ (maximum response), $d$ (log steepness), or $a$ (background response). The most parsimonious models (i.e., the models with lowest AIC) indicated that var (within-group variance) was covariate dependent for PRC and TEM. Dose-response data for each compound, and the fitted exponential functions, are shown in Fig. 3 together with BMD values adjacent to each plot. For both iPMS and TEM, a single dose-response curve fitted the data for all four sampling times; thus, a single BMD value was generated (1.674 and $1.463 \mathrm{mg} / \mathrm{kg}$ for iPMS and TEM, respectively. Although the selected models for BaP and PRC produced BMD values for each sampling time (range: $0.220-0.378$ and $2.195-3.392 \mathrm{mg}$ / $\mathrm{kg}$ for $\mathrm{BaP}$ and PRC, respectively; Fig. 3), overlapping confidence intervals indicated that the four BMD values for each chemical were not significantly different from each other. Collectively, these analyses showed that, over the time span investigated in this study, chemical potency values (i.e., the BMDs highlighted in Fig. 3) were not significantly affected by sampling time. 
$\mathrm{BaP}$

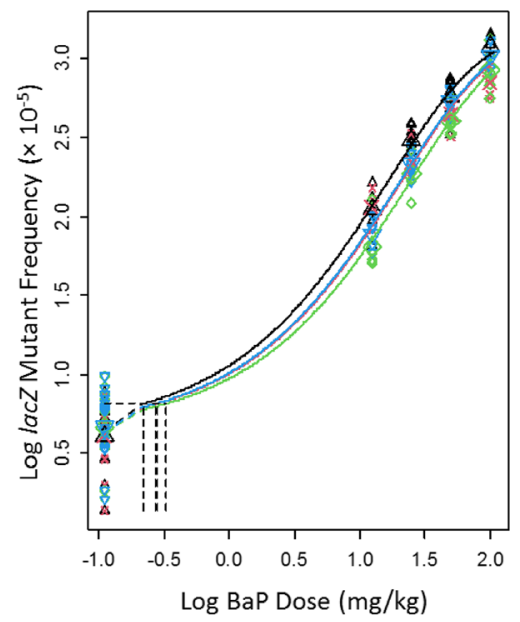

iPMS

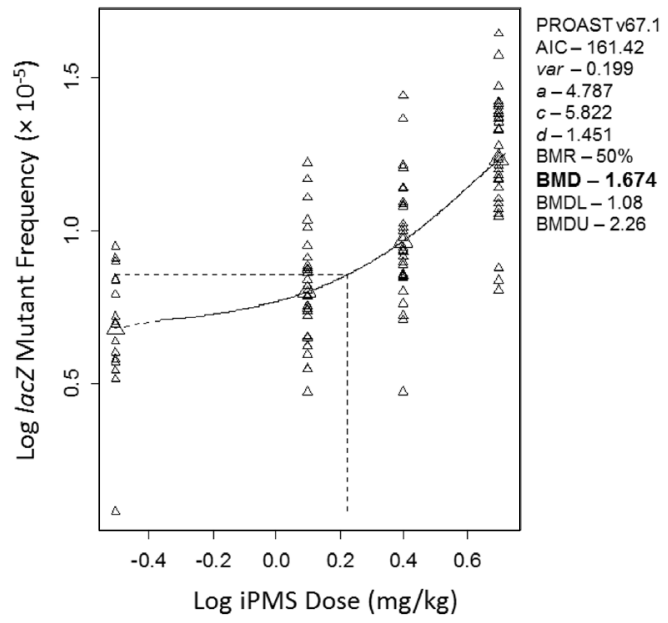

Fig. 3 BMD Analyses of LacZ Mutant Frequency Dose-response Data for Each Tested Substance. PROAST output showing the relationships between Log Response (i.e., lacZ MF $\times 10^{-5}$ ) and Log dose $(\mathrm{mg} / \mathrm{kg} / \mathrm{day})$ for each of the tested substances, and the fitted exponential functions. The functions were selected by minimizing AIC; in all cases the BMR was 50\% (see "Materials and methods"). The horizontal dashed lines indicate the BMR, vertical dashed lines indicate the BMD(s). The text adjacent to each plot show the PROAST output indicating AIC, and estimates of parameters a, c, d, var and BMD.

\section{Discussion}

The objective of this study was to generate critical data to evaluate the suitability of the $28+28 \mathrm{~d}$ design as the only experimental protocol necessary to assess in vivo mutagenicity using OECD TG 488. Such a protocol would permit the simultaneous assessment of in vivo mutagenicity in germ cells and any somatic tissue, irrespective of the proliferation rate, thus, greatly reducing the number of animals required for testing. The results obtained in this study, which
PRC

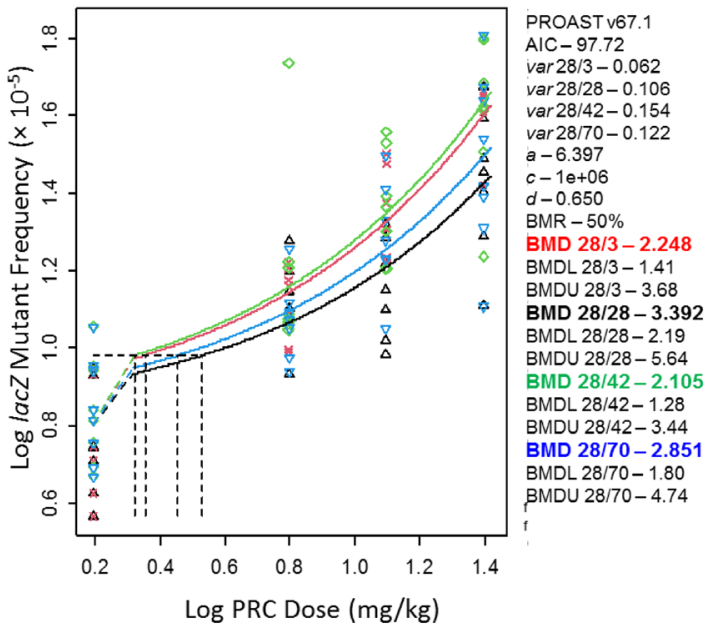

TEM

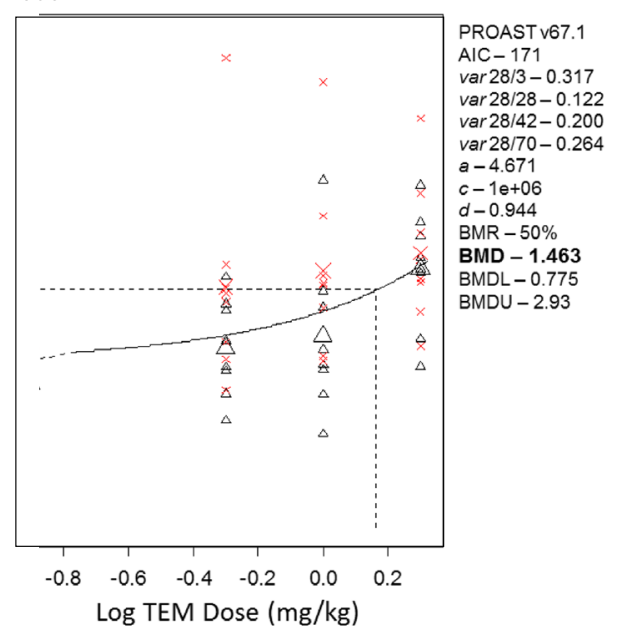

For each BMD, the upper and lower confidence limits are indicated as required. Small plotting symbols show results for individual animals. Where parameters are sampling time dependent, the different colours indicate the different sampling times and the BMD values are indicated using the same colours (red is $28+3 \mathrm{~d}$, black is $28+28 \mathrm{~d}$, green is $28+42 \mathrm{~d}$, and blue is $28+70 \mathrm{~d}$ ). $B a P$ benzo(a)pyrene; $P R C$ procarbazine; iPMS isopropyl methanesulfonate; TEM Triethylenemelamine (color figure online)

was conducted using four chemicals with greatly different fold increases in MF, strongly suggest that extending the sampling time to $+28 \mathrm{~d}$ has no impact on assessing in vivo mutagenicity in BM. Indeed, the analysis of MF in BM at $28+28 \mathrm{~d}$ provides a response that is qualitatively and quantitatively similar to that obtained with the presently recommended design of $28+3 \mathrm{~d}$.

The original decision of selecting $28+3 \mathrm{~d}$ as the recommended design for somatic tissues in TG 488 was prompted by data showing a decline in MF in rapidly proliferating 
tissues (Hara et al. 1999; Thybaud et al. 2003) and concerns that increasing the sampling time for rapidly proliferating tissues could potentially inflate MF because of clonal expansion of mutations, especially when the response was strong (Heddle 1999; Thybaud et al. 2003). In our study, evaluation of MF over the span of 70 days from the end of exposure provided evidence for a decline in induced $\mathrm{MF}$ and suggested that how soon the decline manifests itself is linked to the magnitude of the effect. In the case of TEM, the mutagen that was expected to induce the smallest effect with respect to controls among the four mutagens tested, extending the sampling time past $+28 \mathrm{~d}$ resulted in a qualitatively different outcome. In fact, while the high dose of TEM gave statistically significant increases in MF at $28+3 \mathrm{~d}$ and $28+28$ d, both later sampling times failed to do so. Thus, TEM would be incorrectly classified as non-mutagenic when analyzed more than a month from the end of the exposure. Of note, sequencing of mutant plaques collected at $28+3 \mathrm{~d}$ demonstrated that TEM produced a mutation spectrum that was significantly different from the spontaneous mutation spectrum further supporting its mutagenic effect (Beal et al. 2020).

Additional support for a time-related decline in MF comes from the observation that the low dose of PRC produced a statistically significant effect at all sampling times tested but $28+70 \mathrm{~d}$. Overall, these results support the notion that a decline in induced MF with increasing times from the end of the exposure is possible. A sampling time of 70 days is sufficiently long to result in the elimination from BM of the great majority of mature hematopoietic cells that had been produced while chemical exposure was taking place in both the mouse (Borghans et al. 2018) and the rat (McDonagh 1995). Thus, the decline in MF with time may reflect the differential sensitivity of long-lasting progenitor cells to the induction of mutations with respect to more advanced hematopoietic cell types. Although biologically interesting, these results have little implication for regulatory testing as it is difficult to envision a scenario under which analysis of mutations several months from the end of the exposure would be required to properly assess the hazard.

We found little evidence of increased MF with increasing sampling times as the MF for all chemicals were relatively constant at all four sampling times. MF only appeared to increase with the sampling time for the high dose of $\mathrm{BaP}$ which produced a $>200$-fold increase in MF. Both biological and technical considerations are necessary to properly evaluate this finding. First, the MF obtained with the high dose of $\mathrm{BaP}$ is already extremely high at $28+3 \mathrm{~d}$ approaching what would be expected with a jackpot mutation (Heddle 1999). It is possible that when the magnitude of the effect is this large, clonal expansion of mutations with time could occur to the extent that it becomes measurable. Second, the $\mathrm{BaP}$ results are confounded by the fact that these experiments were conducted at three different times over several years, while the other three chemicals were tested in a single experiment over a shorter period of time. Thus, there are experimental variables that could have played a role in the observed variability in MF at a high dose. Nevertheless, the $\mathrm{BaP}$ results are consistent, both qualitatively and quantitatively, across sampling times. Our results suggest that if there is clonal expansion of mutations with increasing sampling times, this has a negligible outcome for regulatory decision-making based on the TGR data.

Our results provide convincing evidence that observed MF in a rapidly proliferating tissue such as the BM are relatively stable over 70 days after the end of the exposure. Of primary importance for in vivo mutagenicity testing for regulatory decision-making, increasing the sampling time to $+28 \mathrm{~d}$ for the analysis of mutations in the BM yielded qualitatively and quantitatively similar results to those obtained at $+3 \mathrm{~d}$. This conclusion was based on data derived from mutagens spanning two orders of magnitude in the maximum observed MF, i.e., $>200$-fold versus $>$ twofold for $\mathrm{BaP}$ and TEM, respectively. The results with TEM are particularly important because they show that even with a weak mutagen that barely doubles the MF with respect to controls, the $28+28 \mathrm{~d}$ design is unlikely to generate falsenegative results.

The results presented here were obtained in the BM, which is one of the most commonly used tissues in genotoxicity testing. It is of interest to consider how generalizable they are to other rapidly proliferating tissues, such as the small intestine that represents the site of contact for oral exposures. Despite the fact that the epithelium of the small intestine is replaced weekly, MF in the small intestine are relatively stable over 8-10 weeks post exposure regardless of whether the lacI (Tao et al. 1993), lacZ (Cosentino and Heddle 1996), gpt delta (Swiger et al. 2001) or the phiX174 am3 (Cosentino et al. 2002) reporter gene is used. In all of these studies, the authors also showed that MF at the endogenous $\mathrm{Dbl}-\mathrm{l}$ locus are also stable over this period of time. The majority of these results were obtained with single acute doses, but a similar persistence of mutations was also observed when weekly exposures were used (Tao and Heddle 1994). Together with our results, the findings in the small intestine support the notion that MF in rapidly proliferating tissues are stable for several months after the end of the exposure.

There is growing interest in applying quantitative approaches, such as BMD modelling, to analyze genotoxicity dose-response data and determine compound-specific potency (White et al. 2020). The BMD approach, which permits statistical determination of the dose that elicits a pre-defined increase in response over background (i.e., the BMR), has been deemed superior to methods that have been used to determine potency metrics such as NOGEL 
(no observed genotoxic effect level) and Td (threshold dose). The former is dependent on study design (i.e., dose selection and spacing) (Johnson et al. 2014), the latter requires assumptions that are generally not statistically justified. Using the BMD combined-covariate approach, the analyses conducted herein did not reveal any statistically significant impact of sampling time on compound potency (BMD). Thus, with respect to the estimation of a point of departure for quantitative interpretation of in vivo mutagenicity dose-response data, the conducted BMD analyses support the conclusion that, for rapidly proliferating tissues, the $28+28 \mathrm{~d}$ design is as suitable as the $28+3 \mathrm{~d}$ design .

In recent years, increased emphasis has been placed on the use of the historical background control to properly evaluate whether the results of a test are conclusively positive, negative or equivocal (Thybaud et al. 2017). Thus, an important question associated with recommending the use of $28+28 \mathrm{~d}$ as the preferred design for in vivo somatic mutagenicity testing is whether it would require the establishment of a new historical background control at this time point, or whether an existing historical control at $28+3 \mathrm{~d}$ would be appropriate. The analyses of MF in our set of 84 control animals indicate a trend for an age-related increase in spontaneous mutations that approaches statistical significance (e.g., $p=0.06$ ). The age difference between the youngest and oldest mice in our study is $\sim 100$ days, and it is reasonable to assume that the age-related increase in $\mathrm{MF}$ would become statistically significant over a larger age span. Indeed, significant age-related increases in spontaneous mutations have been reported in several tissues using various TGR models (Aoki et al. 2015; Busuttil et al. 2007; Dolle et al. 1997, 2000; Hill et al. 2004) where the age difference between the youngest and oldest animals was larger than that in our study. These studies also demonstrated tissuespecific differences in the age-related increase in mutations; however, these differences became apparent only in much older animals than those used in our study (Aoki et al. 2015; Busuttil et al. 2007; Dolle et al. 1997, 2000; Hill et al. 2004). Importantly, our analyses showed that the age difference associated with extending the sampling time to +28 days from +3 days after the end of exposure is too narrow to have a significant and measurable impact on the observed MF. In fact, regardless of whether MF are analyzed by sampling time or biological age of the animals, there was no significant difference between the first two sampling times. We conclude that an existing historical control generated at $28+3 \mathrm{~d}$ can be applied to new studies conducted at $28+28 \mathrm{~d}$ and that there is no need to re-establish a new historical control database at the later sampling time.

In summary, we provide strong evidence that analyzing MF in rapidly proliferating tissues using the $28+28 \mathrm{~d}$ design, rather than the commonly used $28+3 \mathrm{~d}$ design, does not impact the ability to detect a significant increase in mutations even when a weak mutagen is employed. Furthermore, quantitative dose-response modelling of the $28+3 \mathrm{~d}$ and $28+28 \mathrm{~d}$ data did not reveal any statistical difference in mutagenic potency (i.e., BMD). Obviously, the $28+28 \mathrm{~d}$ design requires maintaining the animals for over three additional weeks with respect to the $28+3 \mathrm{~d}$ design, with associated increased maintenance costs. However, this is compensated by obtaining a more robust assessment of mutations in an important tissue for toxicological studies such as the liver, together with the possibility of using the same animals to assess MF in germ cells, which reduces by half the number of animals needed for testing. The $28+3 \mathrm{~d}$ design remains an appropriate design when there is no need to obtain germ cell data or when the study is conducted in female animals for test substance-related reasons. However, following the recent adoption of the $28+28 \mathrm{~d}$ design as the recommended protocol for germ cell testing (OECD 2020), our results provide robust support for selecting the $28+28 \mathrm{~d}$ design as the recommended protocol in TG 488, and simultaneously assessing mutations in somatic tissues and germ cells of both mice and rats. These results provide critical information for optimizing OECD TG 488 to greatly reduce the number of animals required for regulatory testing.

Acknowledgments The authors would like to thank Drs. Jason O'Brien, Marc Beal and Clotilde Maurice for contributing to the collections of samples that were used to conduct the lac $Z$ assays reported here. This work was supported by the Chemicals Management Plan initiative.

Author contribution Conceptualization: FM, CY, GD; Methodology: GZ, DL; Formal analysis and investigation: GZ, DL, AW, PW; Writing — original draft preparation: FM, GZ; Writing — review and editing: all authors; Funding acquisition: FM, CY; Resources: GZ, AW, PW; Supervision: FM.

Funding Chemicals Management Plan, Health Canada.

Data availability Individual animal mutant frequency data available upon request.

Code availability PROAST in R (version 67.1, https://rivm.nl/en/proas t).

\section{Compliance with ethical standards}

Conflict of interest The authors report no conflicts of interest nor competing interests.

Ethics approval Health Canada Ottawa Animal Care Committee under protocols 2011-020; 2011-024; 2013-010; 2014-016; 2018-010.

Open Access This article is licensed under a Creative Commons Attribution 4.0 International License, which permits use, sharing, adaptation, distribution and reproduction in any medium or format, as long as you give appropriate credit to the original author(s) and the source, provide a link to the Creative Commons licence, and indicate if changes 
were made. The images or other third party material in this article are included in the article's Creative Commons licence, unless indicated otherwise in a credit line to the material. If material is not included in the article's Creative Commons licence and your intended use is not permitted by statutory regulation or exceeds the permitted use, you will need to obtain permission directly from the copyright holder. To view a copy of this licence, visit http://creativecommons.org/licenses/by/4.0/.

\section{References}

Abramsson-Zetterberg L, Zetterberg G, Grawe J (1996) The timecourse of micronucleated polychromatic erythrocytes in mouse bone marrow and peripheral blood. Mutat Res 350(2):349-358. https://doi.org/10.1016/0027-5107(95)00208-1

Aoki Y, Hashimoto AH, Sugawara Y et al (2015) Alterations in the mutagenicity and mutation spectrum induced by benzo[a]pyrene instilled in the lungs of gpt delta mice of various ages. Genes Environ 37:7. https://doi.org/10.1186/s41021-015-0004-x

Beal MA, Gagne R, Williams A, Marchetti F, Yauk CL (2015) Characterizing Benzo[a]pyrene-induced lacZ mutation spectrum in transgenic mice using next-generation sequencing. BMC Genomics 16:812. https://doi.org/10.1186/s12864-015-2004-4

Beal MA, Meier MJ, LeBlanc DP et al (2020) Chemically induced mutations in a MutaMouse reporter gene inform mechanisms underlying human cancer mutational signatures. Commun Biol 3(1):438. https://doi.org/10.1038/s42003-020-01174-y

Bielas JH, Heddle JA (2000) Proliferation is necessary for both repair and mutation in transgenic mouse cells. Proc Natl Acad Sci U S A 97(21):11391-11396. https://doi.org/10.1073/pnas.190330997

Borghans JAM, Tesselaar K, de Boer RJ (2018) Current best estimates for the average lifespans of mouse and human leukocytes: reviewing two decades of deuterium-labeling experiments. Immunol Rev 285(1):233-248. https://doi.org/10.1111/imr.12693

Busch K, Klapproth K, Barile M et al (2015) Fundamental properties of unperturbed haematopoiesis from stem cells in vivo. Nature 518(7540):542-546. https://doi.org/10.1038/nature14242

Busuttil RA, Garcia AM, Reddick RL et al (2007) Intra-organ variation in age-related mutation accumulation in the mouse. PLoS ONE 2(9):e876. https://doi.org/10.1371/journal.pone.0000876

Canadian Council on Animal Care (1993) Guide to the care and use of experimental animals, vol 1. Canadian Council on Animal Care, Ottawa

Coffing SL, Kenyon MO, Ackerman JI, Shutsky TJ, Dobo KL (2015) Evaluation of the in vivo mutagenicity of isopropyl methanesulfonate in acute and 28 day studies. Environ Mol Mutagen 56(3):322-332. https://doi.org/10.1002/em.21910

Cosentino L, Heddle JA (1996) A test for neutrality of mutations of the lacZ transgene. Environ Mol Mutagen 28(4):313-316. https://doi.org/10.1002/(SICI)1098-2280(1996)28:4\%3c313 ::AID-EM3\%3e3.0.CO;2-C

Cosentino L, Malling HV, Heddle JA (2002) Response of the phiX174 am3, cs70 transgene to acute and chronic ENU exposure: implications for protocol design. Mutat Res 518(2):113-121. https://doi. org/10.1016/s1383-5718(02)00078-5

de Rooij DG (2001) Proliferation and differentiation of spermatogonial stem cells. Reproduction 121(3):347-354

Dolle ME, Giese H, Hopkins CL, Martus HJ, Hausdorff JM, Vijg J (1997) Rapid accumulation of genome rearrangements in liver but not in brain of old mice. Nat Genet 17(4):431-434. https:// doi.org/10.1038/ng1297-431

Dolle ME, Snyder WK, Gossen JA, Lohman PH, Vijg J (2000) Distinct spectra of somatic mutations accumulated with age in mouse heart and small intestine. Proc Natl Acad Sci U S A 97(15):8403-8408. https://doi.org/10.1073/pnas.97.15.8403

Gelman A, Hill J (2007) Data analysis using regression and multilevel/ hierarchical models. Cambridge University Press, New York

Gingerich JD, Soper L, Lemieux CL, Marchetti F, Douglas GR (2014) Transgenic rodent gene mutation assay in somatic tissues. Springer Science+Business Media, New York

Hara T, Hirano K, Hirano N et al (1999) Mutation induction by $N$-propyl- $N$-nitrosourea in eight MutaMouse organs. Mutat Res 444(2):297-307

Heddle JA (1999) On clonal expansion and its effects on mutant frequencies, mutation spectra and statistics for somatic mutations in vivo. Mutagenesis 14(3):257-260

Heddle JA, Dean S, Nohmi T et al (2000) In vivo transgenic mutation assays. Environ Mol Mutagen 35(3):253-259. https ://doi.org/10.1002/(sici)1098-2280(2000)35:3\%3c253 ::aid-em $11 \% 3 \mathrm{e} 3.0 . \mathrm{co} ; 2-\mathrm{j}$

Heddle JA, Martus HJ, Douglas GR (2003) Treatment and sampling protocols for transgenic mutation assays. Environ Mol Mutagen 41(1):1-6. https://doi.org/10.1002/em.10131

Hill KA, Buettner VL, Halangoda A et al (2004) Spontaneous mutation in Big Blue mice from fetus to old age: tissue-specific time courses of mutation frequency but similar mutation types. Environ Mol Mutagen 43(2):110-120. https://doi.org/10.1002/em.20004

Højsgaard S, Halekoh U (2018) doBy: groupwise statistics, LSmeans, linear contrasts, utilities. R package version 4.6-2. https:// CRAN.R-project.org/package $=$ doBy

Hori H, Shimoyoshi S, Tanaka Y et al (2019) Integration of micronucleus tests with a gene mutation assay in F344 gpt delta transgenic rats using benzo[a]pyrene. Mutat Res Genet Toxicol Environ Mutagen 837:1-7. https://doi.org/10.1016/j.mrgen tox.2018.09.003

Itoh S, Hattori C, Nakayama S, Hanamoto A (2016) Evaluation of in vivo mutagenicity of isopropyl methanesulfonate by RBC Pig-a and PIGRET assays. Mutat Res 811:106-109. https://doi. org/10.1016/j.mrgentox.2015.11.013

Johnson GE, Soeteman-Hernandez LG, Gollapudi BB et al (2014) Derivation of point of departure $(\mathrm{PoD})$ estimates in genetic toxicology studies and their potential applications in risk assessment. Environ Mol Mutagen 55(8):609-623. https://doi.org/10.1002/em.21870

Lambert IB, Singer TM, Boucher SE, Douglas GR (2005) Detailed review of transgenic rodent mutation assays. Mutat Res 590(13):1-280. https://doi.org/10.1016/j.mrrev.2005.04.002

Lemieux CL, Douglas GR, Gingerich J et al (2011) Simultaneous measurement of benzo[a]pyrene-induced Pig-a and lacZ mutations, micronuclei and DNA adducts in Muta Mouse. Environ Mol Mutagen 52(9):756-765. https://doi.org/10.1002/em.20688

Long AS, Wills JW, Krolak D et al (2018) Benchmark dose analyses of multiple genetic toxicity endpoints permit robust, cross-tissue comparisons of MutaMouse responses to orally delivered benzo[a] pyrene. Arch Toxicol 92(2):967-982. https://doi.org/10.1007/ s00204-017-2099-2

Marchetti F, Aardema M, Beevers C, et al. (2018a) Simulation of mouse and rat spermatogenesis to inform genotoxicity testing using OECD test guideline 488. Mutat Res 832-833:19-28. Corrigendum: Mutat Res, 2019, 844:69. doi:https://doi.org/10.1016/j. mrgentox.2018.05.020

Marchetti F, Aardema MJ, Beevers C, et al. (2018b) Identifying germ cell mutagens using OECD test guideline 488 (transgenic rodent somatic and germ cell gene mutation assays) and integration with somatic cell testing. Mutat Res 832-833:7-18. Corrigendum: Mutat Res, 2019, 844:70-71. doi:https://doi.org/10.1016/j. mrgentox.2018.05.021

Maurice C, O'Brien JM, Yauk CL, Marchetti F (2018) Integration of sperm DNA damage assessment into OECD test guidelines for 
genotoxicity testing using the MutaMouse model. Toxicol Appl Pharmacol 357:10-18. https://doi.org/10.1016/j.taap.2018.08.021

Maurice C, Dertinger SD, Yauk CL, Marchetti F (2019) Integrated in vivo genotoxicity assessment of procarbazine hydrochloride demonstrates induction of pig-a and lacz mutations, and micronuclei MutaMouse hematopoietic cells. Environ Mol Mutagen 60(6):505-512. https://doi.org/10.1002/em.22271

McDonagh M, Bell EB (1995) The survival and turnover of mature and immature CD8 T cells. Immunology 84(4):514-520

OECD (2009) Detailed review paper on transgenic rodent mutations assays, vol ENV/JM/MONO(2009)7, Paris

OECD (2016) Test 474: mammalian erythrocyte micronucleus test, vol Section 4. OECD publishing, Paris

OECD (2020) Test 488: transgenic rodent somatic and germ cell gene mutation assay, vol Section 4. OECD publishing, Paris

O'Brien JM, Beal MA, Yauk CL, Marchetti F (2016) Benzo(a)pyrene is mutagenic in mouse spermatogonial stem cells and dividing spermatogonia. Toxicol Sci 152(2):363-371. https://doi.org/10.1093/ toxsci/kfw088

Pacchierotti F, Bassani B, Leopardi P, Zijno A (1991) Origin of aneuploidy in relation to disturbances of cell-cycle progression. II: cytogenetic analysis of various parameters in mouse bone marrow cells after colchicine or hydroquinone treatment. Mutagenesis 6(4):307-311

Rodriguez-Fraticelli AE, Wolock SL, Weinreb CS et al (2018) Clonal analysis of lineage fate in native haematopoiesis. Nature 553(7687):212-216. https://doi.org/10.1038/nature25168

Shwed PS, Crosthwait J, Douglas GR, Seligy VL (2010) Characterisation of MutaMouse lambdagt10-lacZ transgene: evidence for in vivo rearrangements. Mutagenesis 25(6):609-616. https://doi. org/10.1093/mutage/geq048

Slob W, Setzer RW (2014) Shape and steepness of toxicological doseresponse relationships of continuous endpoints. Crit Rev Toxicol 44(3):270-297. https://doi.org/10.3109/10408444.2013.853726

Sun J, Ramos A, Chapman B et al (2014) Clonal dynamics of native haematopoiesis. Nature 514(7522):322-327. https://doi. org/10.1038/nature13824

Suzuki T, Uno Y, Idehara K et al (1999) Procarbazine genotoxicity in the MutaMouse; strong clastogenicity and organ-specific induction of lacZ mutations. Mutat Res 444(2):269-281

Swiger RR, Cosentino L, Masumura KI, Nohmi T, Heddle JA (2001) Further characterization and validation of gpt delta transgenic mice for quantifying somatic mutations in vivo. Environ Mol Mutagen 37(4):297-303. https://doi.org/10.1002/em.1036
Tao KS, Heddle JA (1994) The accumulation and persistence of somatic mutations in vivo. Mutagenesis 9(3):187-191. https:// doi.org/10.1093/mutage/9.3.187

Tao KS, Urlando C, Heddle JA (1993) Comparison of somatic mutation in a transgenic versus host locus. Proc Natl Acad Sci U S A 90(22):10681-10685. https://doi.org/10.1073/pnas.90.22.10681

Thybaud V, Dean S, Nohmi T et al (2003) In vivo transgenic mutation assays. Mutat Res 540(2):141-151

Thybaud V, Lorge E, Levy DD et al (2017) Main issues addressed in the 2014-2015 revisions to the OECD genetic toxicology test guidelines. Environ Mol Mutagen 58(5):284-295. https://doi. org/10.1002/em.22079

United Nations (2017) Globally harmonized system of classification annd labelling of chemicals GHS. Seventh revised edition edn, New York

Vijg J, Douglas GR (1996) Bacteriophage lambda and plasmid lacZ transgenic mice for studying mutations in vivo. In: Pfeifer GP (ed) Technologies for detection of DNA damage and mutations. Plenum Press, New York, pp 391-410

White PA, Long AS, Johnson GE (2020) Quantitative interpretation of genetic toxicity dose-response data for risk assessment and regulatory decision-making: current status and emerging priorities. Environ Mol Mutagen 61(1):66-83. https://doi.org/10.1002/ em.22351

Wills JW, Long AS, Johnson GE et al (2016) Empirical analysis of BMD metrics in genetic toxicology part II: in vivo potency comparisons to promote reductions in the use of experimental animals for genetic toxicity assessment. Mutagenesis 31(3):265-275. https ://doi.org/10.1093/mutage/gew009

Wills JW, Johnson GE, Battaion HL, Slob W, White PA (2017) Comparing BMD-derived genotoxic potency estimations across variants of the transgenic rodent gene mutation assay. Environ Mol Mutagen 58(9):632-643. https://doi.org/10.1002/em.22137

Yauk CL, Gingerich JD, Soper L, MacMahon A, Foster WG, Douglas GR (2005) A lacZ transgenic mouse assay for the detection of mutations in follicular granulosa cells. Mutat Res 578(1-2):117123. https://doi.org/10.1016/j.mrfmmm.2005.04.011

Publisher's Note Springer Nature remains neutral with regard to jurisdictional claims in published maps and institutional affiliations. 